\title{
Horizontal dialogues and open data: the communication spaces of bottom-up urbanism
}

\author{
José Eduardo Calijuri Hamra \\ IAU-USP | Brazil | zecalijuri@gmail.com
}

SIGRADI2018 Txil congresso de sociedade iberoamericana de gráfica digital 22th conference of the iberoamerican society of digital graphics 07|08|09|novembro|2018 iau usp | são carlos | sp br

\begin{abstract}
The process of overcoming the digital divide has led to the formation of common interest groups. Network communication has become not only a mean, but also a conditioning for the horizontal structure of groups that are also dedicated to transforming urban spaces. Known as processes of bottom-up urbanism, these groups add virtual layers to urban space, and acting in a cybrid way they make inseparable the actions that occur on the virtual or material environment. This research is dedicated to understanding the dynamics of communication in a Facebook group created in one of these bottom-up urbanism processes.
\end{abstract}

Keywords: Bottom-up urbanism; Network society; Facebook; Communication process.

\section{INTRODUÇÃO}

Processos de urbanismo bottom-up são realizados por articulações de grupos e sequência de ações dedicadas à transformação de espaços urbanos de maneira colaborativa. Essas ações são organizadas por grupos autogestionados, com estruturas horizontais e atuando de maneira cíbrida (Beiguelman, 2004). Enquanto definição, o termo "urbanismo bottom-up" não se trata de um conceito estabelecido ou de uma metodologia de ação, mas de uma ampla gama de possibilidades de atividades que viabilizam a transformação de determinados espaços públicos a partir da ação de indivíduos que se organizam de forma autônoma (Hamra, 2018). A característica mais definida destes processos são as relações de independência que, em termos gerais, possuem com entidades privadas e com o próprio Poder Público a fim de garantir a autonomia do grupo. Por outro lado, é exatamente a falta de vínculos com o Poder Público que se torna a fonte dos principais questionamentos a respeito dessa prática.

Trata-se de um fenômeno contemporâneo e transdisciplinar, que agrega indivíduos com as mais diversas formações e está relacionado com conceitos emergentes em diversas áreas de conhecimento, como por exemplo urbanismo tático, DIY (Do it Yourself), DIWO (Do it With Others), economia colaborativa, projeto colaborativo, facilitadores, hackear a cidade, urbanismo P2P, cidade de código aberto, procomún, placemaking, wikipraça, microplanejamento, urbanismo emergente e handmade urbanism.

A grande diferença dos fenômenos contemporâneos em relação a práticas comunitárias tradicionais, como mutirões ou associações de vizinhos, está pautada exatamente na formação e atuação dos grupos no espaço híbrido, ou seja, nos encontros e diálogos que se estabelecem de forma única entre o espaço físico e o virtual. De acordo com Clay Shirky (2011), a formação de grupos de interesses comuns que se conectam por meio do espaço virtual é uma tendência que cresce de maneira exponencial à medida que a brecha digital é superada e a sociedade em rede se consolida. É, portanto, o potencial do espaço híbrido que coloca o fenômeno contemporâneo do urbanismo bottom-up como um novo ator de transformação urbana iniciado no século XXI, como apontado por Hamra (2018).

De acordo com Manuel Castells (2009 e 2013), ao analisar movimentos sociais contemporâneos, é o processo de comunicação dos grupos que determina sua estrutura e atuação. Para Clay Shirky (2012), em consonância com Castells (2013), a conectividade no espaço virtual e a consolidação da sociedade em rede favorecem a "formação de grupos ridiculamente fácil". Nunca foi tão acessível encontrar pessoas, assuntos e causas com as quais nos identificamos e nos dedicamos por prazer ou empatia. Por meio de hiperlinks, buscadores e redes sociais digitais podemos nos associar, conectar e trabalhar coletivamente para o desenvolvimento de propósitos comuns.

Não se deve esquecer, entretanto, que essas possibilidades de encontro não ocorrem exclusivamente pela estrutura física das redes de internet, mas sim nos espaços virtuais privados construídos por empresas que oferecem esses serviços. A conectividade a determinados temas e indivíduos pode estar sujeita a interesses privados das empresas que regulam estes espaços, por isso é importante estar claro que não se tratam de espaços públicos virtuais. Não se pode negar, entretanto, como argumentado por Shirky (2012), que os custos gerenciais de manutenção de grupos, tradicionalmente atrelados a atividades físicas, foram superados por esses serviços e disponibilizados por essas empresas, o que na prática tem facilitado essas articulações sociais.

Ao criar um grupo público em uma rede social digital, como por exemplo o Facebook, abre-se um espaço de fala organizado e de atividade constante, nos quais diálogos, datas, palavras chaves, vídeos, fotos e textos podem ser facilmente encontrados, copiados, divulgados e encaminhados. Facilitou-se, inclusive e sendo de 
extrema importância para grupos que atuam com pautas urbanas, a participação de pessoas distantes fisicamente dos locais em debate ou que, impossibilitadas pelo custo de deslocamento nas metrópoles, não conseguiriam estar presentes em atividades presenciais.

Manuel Castells (2013), ao analisar a Primavera Árabe, demonstra que o espaço virtual favoreceu o encontro dos indivíduos e a formação dos grupos por meio do encontro dos descontentamentos. Em termos práticos, os cidadãos indignados, ao se manifestarem no espaço virtual, se aproximaram, se encontraram e passaram a interagir com outros indivíduos que ansiavam por mudanças semelhantes. Assim, manifestando suas indignações nas redes virtuais, os indivíduos se encontraram e se conectaram, empoderando-se como grupos e articulando ações de grande magnitude.

Como descrito por Castells (2013), os processos de comunicação e articulação de atividades em grupos, estruturados por caminhos híbridos nestes movimentos sociais, talvez sejam mais significativos, inclusive, que as próprias conquistas práticas obtidas em alguns casos. A partir das pesquisas de Freitas (2015), Carneiro (2012), Hamra (2018), Baptista e Espinoza (2016) pode-se dizer que a Primavera Árabe, os Movimentos Occupy e as Jornadas de Junho, muito além das conquistas nas causas pelas quais protestavam, foram demonstrações práticas, em larga escala, da internet e das redes sociais digitais sendo utilizadas como possíveis ferramentas de articulação de grupos e transformação social.

O impacto desses movimentos sociais que pretende-se destacar nesta pesquisa diz respeito a proliferação da cultura organizacional que se desenvolveu e proliferou para formações de grupos que atuam com distintas pautas, como a própria transformação das cidades. No caso específico dos movimentos dedicados a transformação urbana, por serem germinados em uma cultura organizacional pautada na autogestão de grupos horizontais, que se estruturam de maneira híbrida, com ações e diálogos tanto no espaço físico como no virtual, é que são denominados, de maneira ampla, como "processos de urbanismo bottom-up".

Para que fique claro quem são os atores envolvidos nesses processos é preciso ter em mente que, mesmo se tratando de um único espaço a ser transformado, diversos grupos se formam com as mais variadas intenções. Cada grupo atua a partir de uma dinâmica própria, organizada de maneira horizontal pela convivência que se desenvolve entre os membros. No caso do Largo da Batata, objeto de estudo desta pesquisa, verificam-se grupos que atuam, por exemplo, com mobiliário urbano, com música eletrônica, plantio e manutenção de espécies vegetais e da própria limpeza do Largo. Todos esses grupos e atores, no caso do Largo da Batata, possuem além do próprio espaço físico do Largo da Batata, um espaço de comunicação virtual, que é o grupo criado na rede social digital Facebook, recorte de estudo desta pesquisa.

O grupo em questão, de nome "A BATATA PRECISA DE VOCÊ" (Facebook id: 602802213101983), é administrado por membros que também administram uma página de Facebook de mesmo nome. Vale ressaltar, entretanto, que a página é pertencente apenas a um dos grupos de atores que atuam na transformação física deste espaço. Já o grupo, por ser aberto a postagens dos membros e seu formato favorecer o diálogo, agrega diversos outros grupos e atores individuais que realizam atividades no Largo. Também é preciso levar em consideração que os próprios grupos não são formados por indivíduos necessariamente semelhantes, mas sim por um interesse comum, como por exemplo o plantio de árvores, o que atrai indivíduos com diferentes experiências.

Tendo em vista que o problema estudado por esta pesquisa são os processos de urbanismo bottom-up e que a literatura especializada indica que o engajamento desses grupos, assim como sua estrutura organizacional, se dão por meio dos espaços virtuais de comunicação, o foco da pesquisa em analisar um desses espaços de comunicação se justifica como um passo necessário na compreensão desse fenômeno de transformação urbana.

O fato dos grupos atuarem e se comunicarem também nas redes sociais digitais não favorece apenas a atuação do próprio grupo, mas por meio da geração e disponibilização de dados e informações geram-se novas possibilidades e ferramentas para se compreender dinâmicas urbanas e sociais referentes às cidades. Como argumenta André Lemos (2008), ao nos deslocarmos pelas cidades portando dispositivos móveis conectados à rede de internet e ao nosso corpo, estamos digitalizando nossas ações e as disponibilizando para serem usadas de outras formas. Esse fenômeno de geração de dados referentes ao espaço urbano e a nossas atividades pessoais, como argumenta Panagoulia (2017), nos possibilita novas formas de compreender a cidade e novas ferramentas para alterá-la. É neste sentido, inclusive, que essa pesquisa desenvolveu sua metodologia própria, por meio da análise de um grupo público em uma rede social digital, para analisar um processo de transformação urbana.

Espera-se com esse artigo fornecer, do ponto de vista da metodologia, uma possibilidade de ferramenta para leitura urbana a partir dos dados disponibilizados de maneira aberta em uma rede social digital. A relevância desta pesquisa, do ponto de vista da discussão teórica, se concentra especialmente no debate do impacto da sociedade em rede na formação de grupos autogestionados, do papel da comunicação distribuída para a formação e atuação desses grupos e principalmente na elucidação, ainda que parcial, dos processos de urbanismo bottom-up.

\section{METODOLOGIA}

A seleção do Largo da Batata, enquanto espaço físico no qual ocorre um processo de urbanismo bottom-up levou em consideração fatores como i) a longevidade das ações e atividades promovidas no espaço, ii) a atuação e permanência, ou seja, a ocupação constante do espaço público, iii) conhecimentos pré-adquiridos sobre o espaço, seu desenvolvimento histórico, sua relação com a cidade e seu contexto social.

Uma vez definido o local e consequentemente o processo de urbanismo bottom-up que seria analisado, a pesquisa selecionou a rede social digital Facebook como fonte de dados que seria consultada. Para tal seleção foram 
levados em consideração os seguintes critérios i) o fato do Facebook ser a rede social mais utilizada do Brasil, logo com a possibilidade de participação maior e mais diversa, ii) o fato de ser uma rede social que disponibiliza dados abertos em larga escala, iii) a facilitação de busca desses dados por APl's próprios da plataforma (vale ressaltar que no ano de 2018, devido ao vazamento de dados dos usuário do Facebook, as API's e aplicativos da plataforma estão sendo revistas e bloqueadas de acordo com novas políticas de privacidade da empresa). Claramente, também foi verificado por meio de pesquisa prévia que essa é a rede social mais utilizada pelos indivíduos e grupos que atuam com o processo bottom-up no Largo da Batata.

Como o foco da pesquisa é o espaço de comunicação nos processos de urbanismo bottom-up, percebeu-se, por meio da análise das tipologias de espaço disponibilizados pelo Facebook, que um "grupo" seria o melhor espaço para ser analisado. Isso deve pela própria estrutura de comunicação disponibilizada nos espaços de "grupos", que permite diversas formas de interação, de comunicação por diferentes mídias e de contato com membros, entre outros. Neste sentido foi selecionado o grupo de Facebook "A Batata Precisa de Você", o que levou em consideração critérios como i) quantidade de membros (6533) ; ii) a frequência de postagens ; iii) a diversidade de temas tratados ; iv) a relação dos temas tratados com o que de fato ocorria na praça e v) a presença de membros no grupo que realmente executam as atividades de urbanismo bottom-up.

Uma vez feitas as aproximações do recorte da pesquisa, caminhando da seleção do processo de urbanismo bottom-up ao grupo de Facebook, optou-se por utilizar a API Netvizz como ferramenta de extração de dados do grupo selecionado (vale ressaltar que o Netvizz é uma das API's que pode se tornar inoperante devido as novas políticas de privacidade do Facebook). O método utilizado, dentro do Netvizz, para fazer a extração foi o "group data", pelo qual foram coletados e sistematizados em 15 categorias todos os dados de atividades realizadas no grupo desde a sua fundação em 21 de março de 2014 até 29 de dezembro de 2017. Os dados extraídos foram categorizados em 15 variáveis, sendo elas: "type" (tipo de postagem, como por exemplo links, fotos, vídeos, etc...), "by" (identificação numérica do responsável pela postagem), "post-id"(identificação de cada postagem realizada por uma identificação numérica). "post_link" (endereço eletrônico com hyperlink para acesso de cada postagem), "post_message" (mensagem textual realizada com cada postagem), "picture" (endereço virtual para acesso em baixa resolução à imagens postadas), "full_picture" (endereço virtual para acesso em alta resolução à imagens postadas), "link" (endereço eletrônico de links que tenham sido postados no grupo), "link_domain" (proprietário de links postados no grupo), "post_published" (data com ano, mês, dia e hora que a postagem foi realizada), "likes_count_fb" (quantidade de likes que uma postagem recebeu), "comments_count_fb" (quantidade de comentários que uma postagem recebeu), "reactions_count_fb" (quantidade de reactions (emojis) que uma postagem recebeu somados a quantidade de likes), "share_count_fb" (quantidade de vezes em que uma postagem foi compartilhada), "engagement_fb" (métrica realizado pela soma de reactions, comentários e compartilhamentos que uma postagem recebeu para verificar seu poder de engajamento).

Ao todo foram coletadas e analisadas 6.107 postagens divididas entre vídeos, links, fotos, status, eventos e notas. Todo o material coletado, dividido nessas categorias de publicação e com as 15 classificações apontadas no parágrafo anterior, foi sistematizado em planilhas e posteriormente em gráficos. A manutenção dos nomes de algumas categorias na língua inglesa se deve ao fato de ser a linguagem utilizada pelo próprio Netvizz em suas formas de extração. Espera-se, com essa manutenção, facilitar a replicabilidade desta metodologia e a comparação com outros estudos que já utilizam a mesma ferramenta.

O critério de qualifiação do nível de envolvimento dos indivíduos com as postagens foi baseado nos 3 níveis de interação disponíveis no Facebook, reactions (reações), comments (comentários) e share (compartilhamento).

As "reações" são a forma menos qualificada e mais usual de interação, são realizadas por meio do botão "like" e mais 5 ícones que representam emoções em relação ao conteúdo postado. Os "comentários" são a qualificação intermediária de interação por pressuporem maior tempo de dedicação do que as reações, e ocorrem quando o usuário utiliza o campo de comentários disponibilizado pelo Facebook para escrever uma mensagem ou criar um hiperlink com outro usuário para que visualize a mesma postagem (a realização deste canal via hiperlink com outro usuário é conhecido no Brasil como "marcar uma pessoa"). Já nos compartilhamentos, forma mais qualificada de interação, os usuários não apenas apenas interagem, mas compartilham o conteúdo postado em suas próprias páginas pessoais ou de terceiros para ampliar a divulgação do conteúdo. O grande diferencial na qualificação desta interação é que o usuário não apenas interage com a publicação, mas passa a ser seu difusor e a aumentar o alcance da postagem para que impacte mais pessoas.

\section{RESULTADOS}

Os resultados obtidos indicam que ao total foram realizados 6.093 postagens no período analisado, as quais receberam 74.954 reações, 21.279 comentários, 1.262 compartilhamentos. Essas informações são apresentadas de maneira sistematizada no gráfico 01 , que, de forma cronológica apresenta os fluxo de "post_published" (publicações realizadas) e os 3 níveis de interação com elas: "reactions_count_fb" (reações), "comments_count_fb" (comentários) e "share_count_fb" (compartilhamentos).

Como pode-se observar, para comprovar os critérios de qualificação adotados para as interações, o fluxo das postagens ocupa uma posição central no gráfico, que tem em primeiro lugar as reações, seguidas pelos comentários e apenas abaixo do número de postagens seguem os compartilhamentos. O que se percebe em termos práticos é a efetividade deste espaço de comunicação, no qual praticamente todas as postagens receberam um elevado nível de comentários e reações. Já o número de compartilhamento das postagens, como era de se esperar, segue bem abaixo do número de postagens, gerando apenas em alguns meses de 2017

3 


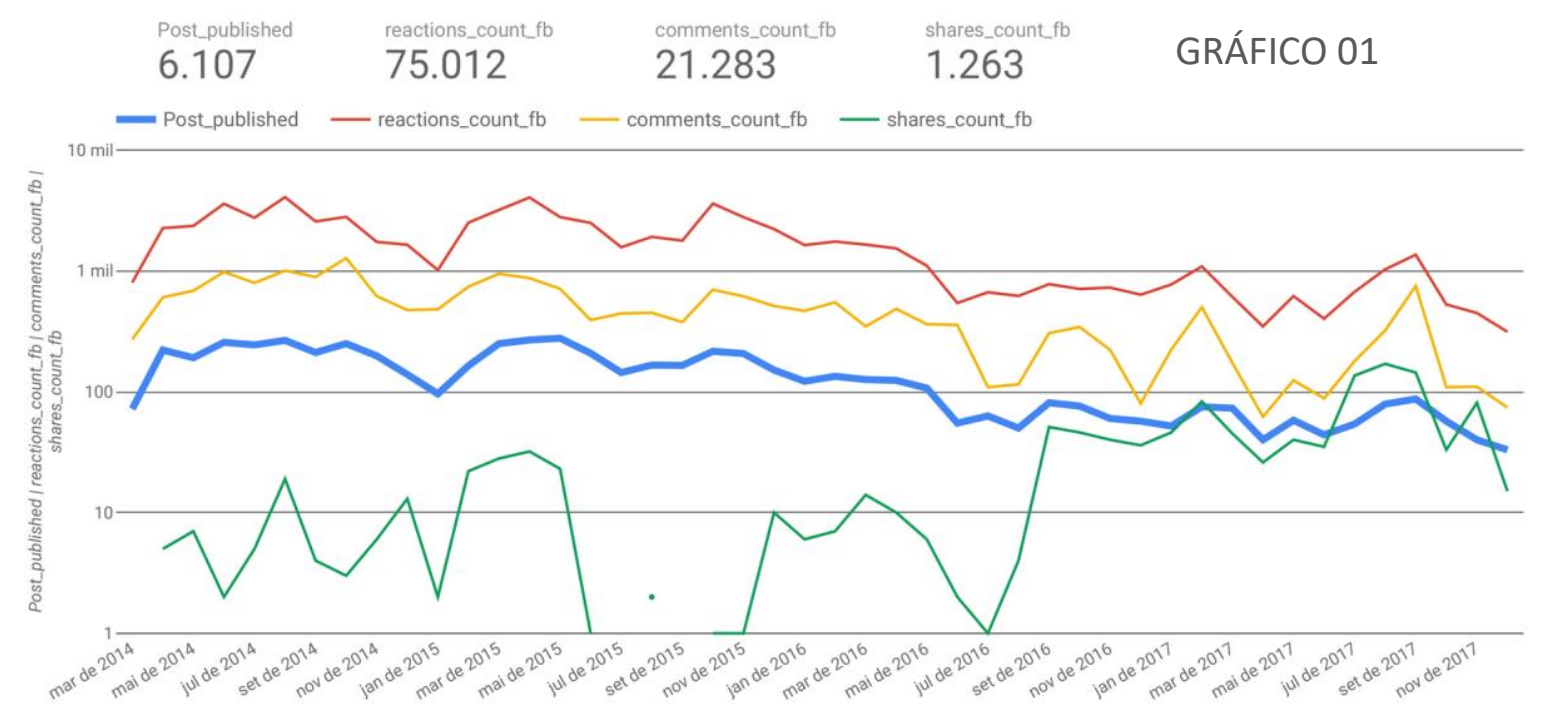

GRÁFICO O1A

Lınha de tendência das "reactions"

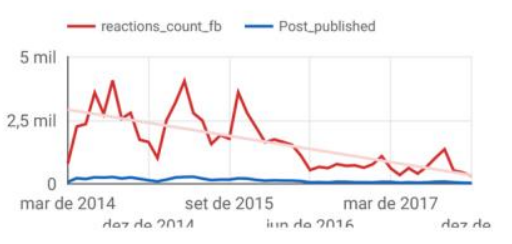

\section{GRÁFICO O1B}

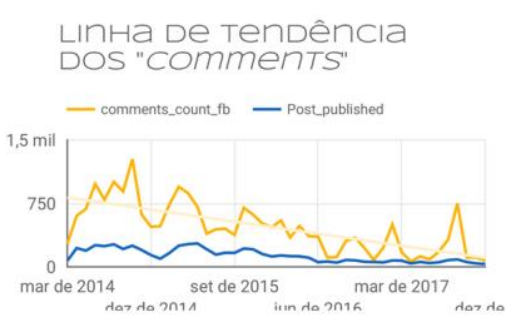

GRÁFICO O1C

Lınha de tendêncıa dos "shares"

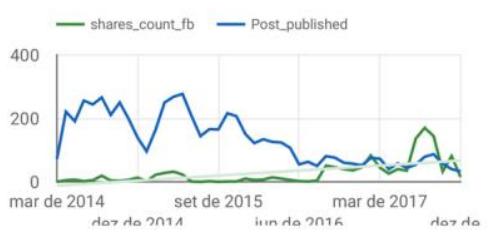

Gráfico 01: histórico das postagens e interações. Fonte: Autor.

Gráficos $01^{\mathrm{A}, \mathrm{B}, \mathrm{C}}$ : curvas de tendência dos níveis de interação.

um fenômeno atípico, em que o número de compartilhamentos supera o número de postagens. Vale observar que em julho de 2017 o número de compartilhamentos quase se iguala ao número de comentários. Esses fatores indicam que embora exista uma pequena diminuição no número de postagens ao longo do tempo, a interação com elas foi se qualificando.

Nos gráficos 1A, 1B e 1C é possível visualizar a curva de tendência de cada uma das interações, que corroboram com o indicativo de que embora sejam cada vez menos volumosas são cada vez mais qualificadas. Como podese observar, a principal queda (gráfico 1A) ocorre com as "reactions", seguidas de maneira quase idêntica por "comments" (gráfico 1B). Já os "compartilhamentos", forma mais qualificada de interação, demonstra um elevado crescimento (gráfico 1C).

Os gráficos 02 A, B e C demonstram, respectivamente, o comportamento isolado de "reactions", "comments" e "shares" ao longo do tempo e em relação ao número de postagens. Embora parte desta informação esteja presente no gráfico 01, nesta apresentação é possível visualizar como, no decorrer dos meses, as interações por "share" são as que demonstram melhor desempenho.

Para avançar na compreensão de como os indivíduos se comunicam neste espaço foi construindo o gráfico 03 , que demonstra quais as mídias mais utilizadas nas postagens do grupo. Das 6.093 postagens, as fotos foram o meio predominante (2.264 postagens), com $37,2 \%$ do total, já a segunda e terceira colocações ficaram quase empatadas, com 23,8\% de "links" (1.449) e 23,4\% de "status" (1.426). Os "events" (eventos) são responsáveis por $8,8 \%$ (539) das postagens no grupo, seguido por "vídeos" que representam 6,8\% (414) do total, e por fim apenas uma postagem em formato de "note" foi realizada.

A próxima etapa de sistematização dos resultados deu origem aos gráficos $4 \mathrm{~A}, \mathrm{~B}$ e $\mathrm{C}$, que demonstram como cada uma das 6 categorias (photo, link, status, event, video e note) de postagem possui uma performance própria com os 3 possíveis níveis de engajamento (reaction, comment e share). O gráfico 4A demonstra, por exemplo, que a categoria "fotos", que representa $37,2 \%$ do total de postagens (ver gráfico 3 ), recebeu $51,6 \%$ do total de "reactions". Essa informação pode ser um indicativo de que a popularidade da categoria fotos se justifique pelo bom engajamento que promovem. Já as categorias que ocupam a segunda e a terceira colocação no gráfico 3, com respectivamente $23,8 \%$ (link) e $23,4 \%$ (status) sofrem ligeira queda no gráfico $4 \mathrm{~A}$, representando apenas $19,6 \%$ e $17,6 \%$ do total de reactions, mas se mantém nas mesmas posições. Uma pequena alteração ocorre com a categoria "event", que representa $8,8 \%$ do total de postagens mas apenas 5,2\% do total de "reactions", ficando atrás de "video", que dos $6,8 \%$ do total das postagens angaria $6,1 \%$ do total de "reactions" e assegura a quarta posição.

No gráfico 4B é possível observar quanto cada uma das categorias de postagens recebeu do total de "comments". A categoria "photos", por exemplo, continua liderando e com um aumento significativo, passando dos $37,2 \%$ do total de postagens que ela representa (ver gráfico 3 ) à receber $46,1 \%$ do total de "comments". Embora aconteça o aumento também neste nível de engajamento, é interessante observar que ele já não é tão representativo quanto na quantidade de "reactions" (ver gráfico 4A) que as "photos" receberam. 

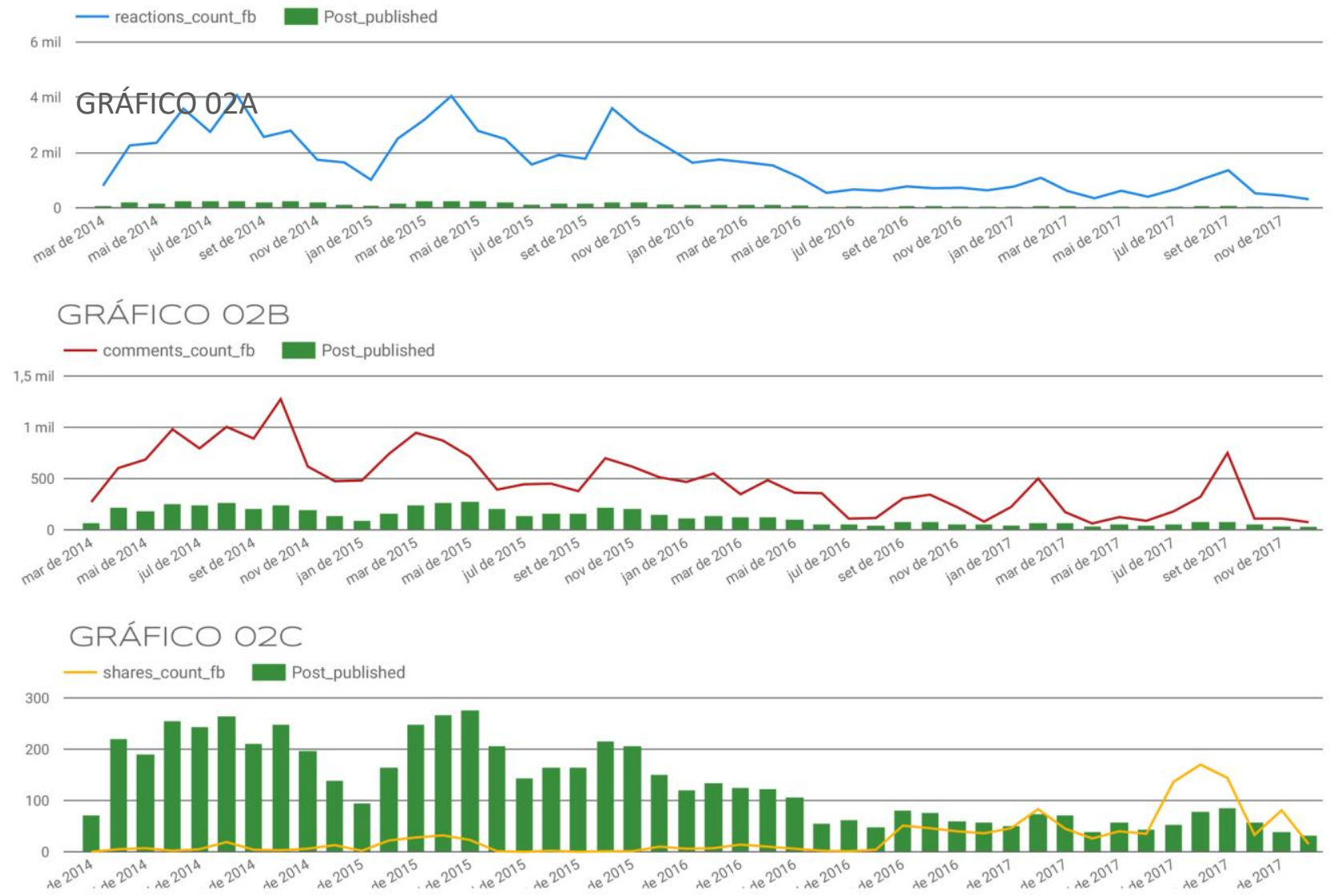

Gráficos 02 A, B, C: histórico das interações em relação ao fluxo de postagens. Fonte: Autor.

O destaque deste gráfico (4B) fica por conta da categoria "status", que representa apenas $23,4 \%$ do total de postagens (ver gráfico 3) mas recebe $34,1 \%$ do total de "comments", subindo para a segunda colocação do gráfico e derrubando "link", com apenas 12,2\%, para a terceira posição. As outras três categorias ("vídeos", "event" e "note") não possuem boa interatividade por comentários, e juntas somam apenas $19,85 \%$ do total recebido.

O gráfico 4C demonstra como foram as interações por "share" com as publicações. Neste caso a categoria "photos" continua na primeira colocação (50,4\%) e recupera um percentual semelhante ao do gráfico $4 \mathrm{~A}$ $(51,6 \%)$. As duas colocações seguintes também são ocupadas, respectivamente, por "link" e "status" com

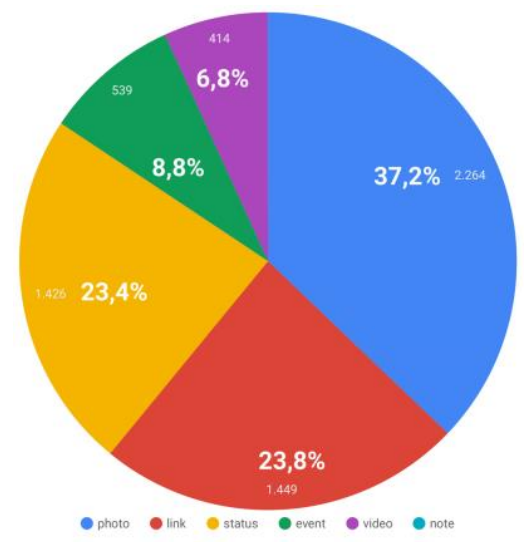

Gráfico 03: porcentagem de cada categoria no total das postagens. Fonte: Autor.

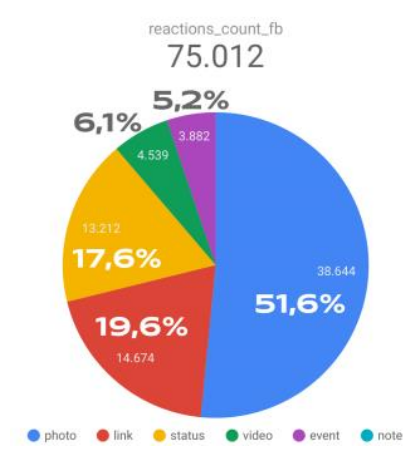

Gráfico 4A: porcentagem de "reactions" em cada categoria. Fonte: Autor.

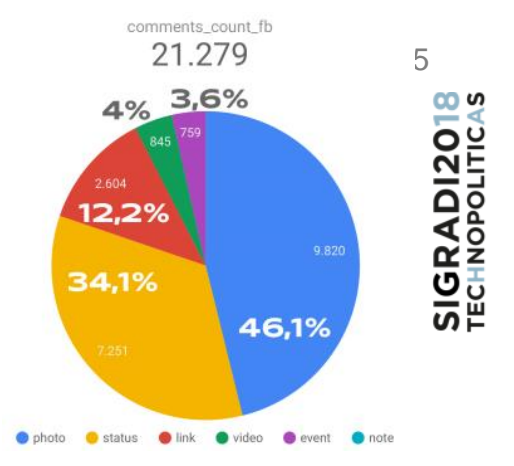

Gráfico 4B: porcentagem de "comments" em cada categoria. Fonte: Autor.

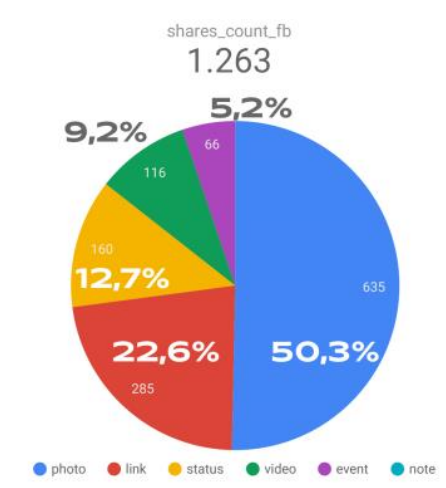

Gráfico 4C: porcentagem de "shares" de cada categoria. Fonte: Autor. 
$22,6 \%$ e 12,7\%, remontando a classificação do gráfico 4A. Embora os valores absolutos não sejam os mesmos e guardando as devidas proporcionalidades, pode-se observar que a performance das categorias nas interações por "reaction" e "share" são semelhantes.

Uma vez realizada a análise dos níveis de interação com cada uma das categoria de postagem, a pesquisa se dedicou a compreender se o fluxo de postagem de cada categoria se manteve constante e/ou em variações semelhantes ao longo do período analisado. Neste sentido, apresenta-se o gráfico 5 , no qual estão dispostas de maneira cronológica o comportamento de postagens divididos em suas 6 categorias.

A análise deste gráfico (5) demonstra que embora a frequência temporal tenha sofrido com oscilações, as categorias se movimentaram de maneira razoavelmente semelhantes, inclusive na diminuição gradual do fluxo de postagens. Vale ressaltar, que embora tenha ocorrido essa significativa redução de postagens, as curvas de tendência indicam que a partir de março de 2017 há uma aparente estabilização deste fluxo, que tende a um discreto crescimento para os meses seguintes. No que diz respeito a análise das linhas próprias de cada categoria, ressalta-se apenas uma pequena desproporcionalidade, que ocorre com o fluxo de postagens de "photos" entre os meses de junho e outubro de 2017.

\section{DISCUSSÃO}

Embora a diminuição no fluxo de postagens possam indicar um desinteresse gradual em relação ao processo de urbanismo bottom-up, é preciso considerar como postagens ao longo do período analisado. Se, por um lado, os dados indicam que os processos de urbanismo bottom-up não conseguem sustentar 0 volume de engajamento por um longo período, por outro, indicam a formação de uma comunidade menor, porém mais sólida e engajada nas ações. Embora no gráfico 01 o aumento das interações qualificadas possa estar relacionado com a alteração dos algoritmos do Facebook que ocorreram em janeiro de 2017, a estabilização e até o aumento do fluxo de postagens (Gráfico 05) nesse mesmo período demonstram que, de fato, houve uma alteração prática também na atividade de postagem, não apenas na interatividade com elas. Neste sentido, os resultados práticos analisados não podem ser analisados em termos de causa e consequência, mas deve-se levar em consideração, mais uma vez, o potencial que o Facebook possui para influenciar o tráfego das informações entre os membros.

De acordo com Clay Shirky (2012) existem 3 níveis de interação que um grupo precisa realizar para construir ações coletivas de transformação, e todos eles são potencializados com a atuação do grupo no espaço híbrido. O nível mais fácil de interação é o "compartilhamento", ou seja, indivíduos que compartilham interesses comuns nas redes sociais digitais se aproximam e criam, por meio de links no espaço virtual, uma comunidade ou grupo, e ainda que não atuem juntos, são reconhecidos como grupo social. O segundo nível de interação é a "cooperação", que além do simples compartilhamento de interesses comuns envolve 0 alinhamento entre duas partes. Já o nível mais complexo de interação é a "ação coletiva", que exige um alinhamento de expectativa em relação ao que será produzido e envolve, acima de tudo, os diálogos e a necessidade de produzir algo pela vontade do grupo

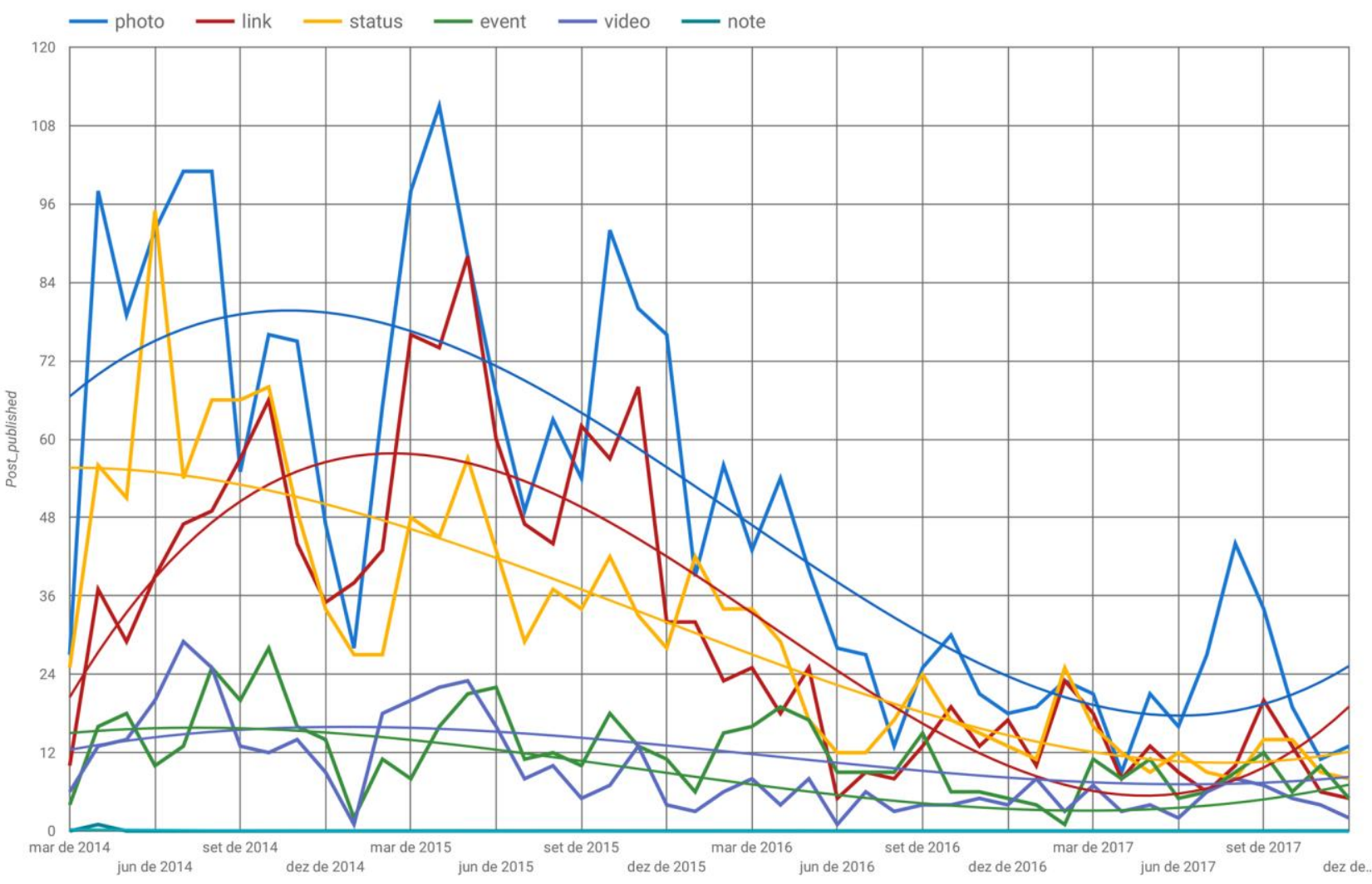

Gráfico 05: fluxo de utilização e curva de tendência de cada categoria de postagem. Fonte: Autor. 
mesmo que seja diferente da vontade individual.

Ao analisar o grupo no Facebook baseado na teoria de Shirky (2012), percebe-se que a diminuição no envolvimento com o grupo é natural, e progride à medida que o nível de interação com as ações promovidas se torna mais complexo. Como percebido nos resultados, é possível que a estabilização do engajamento com as postagens a partir de março de 2017 talvez indique o ponto de estabilidade entre indivíduos que estão, de fato, dispostos a trabalhar com os 3 níveis de interação. Neste sentido é preciso estar claro que a movimentação no grupo de Facebook, como demonstrado por Hamra (2018), está diretamente ligada com as atividades no próprio Largo, o que comprova a atuação de forma realmente híbrida.

Do ponto de vista do processo de comunicação, é interessante observar como a categoria "status" recebe uma quantidade significativa de comentários (comments). Esse fenômeno pode ser um indicativo da diferença de interatividade que uma "comunicação em primeira pessoa" (como ocorre nas postagens via "status"), ao humanizar o diálogo no meio virtual, pode gerar entre os membros do grupo. Ainda que não se possa estabelecer relações afirmativas de causa e consequência neste fenômeno, é importante ter em vista o potencial desta forma de comunicação neste espaço.

Já a popularidade das "photos" no total de "reactions" e "share", podem ser um indicativo de que neste meio, mensagens rápidas são mais visualizadas, provavelmente por não demandarem tempo e esforço do "espectador", o que aumenta a probabilidade de engajamento. Ainda que não se pretenda construir qualquer guia ou método de comunicação para processos de urbanismo bottom-up, é interessante observar como a análise do comportamento de cada categoria de postagem indica estratégias diferentes de comunicação. Neste sentido, os resultados apresentados buscam auxiliar na compreensão de como as dinâmicas dos espaços de comunicação podem ajudar a fortalecer e manter a comunidade engajada ao longo do tempo.

Do ponto de vista da analogia destes movimentos com a Primavera Árabe e movimentos Occupy, é interessante observar que, guardadas as devidas proporções, a comunicação no espaço híbrido se repete como fator estruturante do grupo e de promoção de ações. Por meio do espaço virtual criado pelos membros, informações são trocadas, ações convocadas, plebiscitos realizados e assinaturas são coletadas de forma horizontal e aberta ao diálogo e participações. Como coloca Castells (2009) a respeito dos movimentos sociais, a comunicação encontra seu papel estruturante no engajamento das transformações sociais, e neste caso, urbanas.

O fato dos processos de urbanismo bottom-up se estruturarem em um espaço híbrido e disponibilizarem dados no espaço virtual, como por exemplo no grupo de Facebook analisado, permite que envolvidos em outros processos os utilizem como referência e que mais pesquisas sejam realizadas. Não se trata, entretanto, de um fenômeno democrático em um espaço público, mas de uma camada virtual de dados referentes ao espaço urbano que fica restrita a um espaço privado. Ainda que as atividades analisadas pareçam ter cunho democrático e estarem efetivamente abertas às participações, é preciso estar claro que as atividades em espaços virtuais como o Facebook ocorrem em um espaço privado, portanto, sujeito as relações de interesse.

Tendo em vista que grande parte dos questionamentos em relação aos processos de urbanismo bottom-up ocorrem devido às relações, ou ausência de relações, com o Poder Público, é importante que se considere também os vínculos que estes processos estabelecem com empresas privadas que disponibilizam seus espaços de atuação no meio virtual, como o próprio Facebook. Neste sentido, é necessário debater o fornecimento de dados pessoais, de dinâmicas urbanas e sociais a empresas privadas, o que as potencializa a compreender as cidades com um volume de dados e informações que o próprio Poder Público desconhece.

Não se trata, claramente, de nenhuma acusação ou debate a respeito de qualquer caso concreto, mas da necessidade de se debater um posicionamento do Poder Público. Como dúvida, fica a questão: se a proposta é alterar um espaço urbano público de maneira democrática e sem qualquer caráter privatista, será o espaço virtual privado o meio mais adequado para se realizar essas ações? O que está em jogo ao disponibilizarmos essas informações e quais são os riscos? Claramente, a permeabilidade de redes sociais como o Facebook, sua facilidade de uso e número de membros é indiscutível e o faz, em termos práticos, o caminho mais fácil para coordenar essas ações, mas se fazem cada vez mais necessárias as ponderações dos riscos que se corre.

No que diz respeito a atuação do próprio Facebook, e como última discussão aqui proposta, vale observar que após escândalos de vazamento de dados ainda em 2018, o próprio Facebook alterou sua missão de "fazer do mundo um lugar mais aberto e conectado" para "dar poder para as pessoas construírem comunidades e se aproximarem". Neste sentido, é preciso ter em conta e deixando clara a contribuição desta pesquisa para futuras investigações, que a mudança de postura do Poder Público para os processos de urbanização contemporâneos, passa também, provavelmente, pela discussão de espaços públicos efetivos na esfera virtual.

\section{REFERÊNCIAS}

Baptista, P. C. L.; Espinoza, J. C. H. (2016). Beyond the Jornadas de Junho. Revista Brasileira de Estudos Urbanos e Regionais. Recife, v. 18, (n. 2, pp. 275-290).

Beiguelman, G. (2004). Admirável Mundo Cíbrido. In: Brasil, A.; Alzamora, G.; Falci, C. H.; Jesus, E. de. (Org.). Cultura em Fluxo: Novas mediações em Rede (1 $1^{\underline{a}}$ ed. v.1, pp. 264-282) Belo Horizonte: PucMinas.

Carneiro, H. S. (2012). Apresentação - Rebeliões e ocupações de 2011. In I. Jinkings, \& B. Leme (Eds.), Occupy: movimentos de protesto que tomaram as ruas (1a ed, pp. 5764). São Paulo: Boitempo \& Carta Maior.

Castells, M. (2009). Comunicación y Poder. 1르 Edição. Madrid: Alianza Editorial.

Castells, M. (2013). Redes de Indignação e Esperança: movimentos sociais na era da internet. $1^{\text {a }}$ Edição. Rio de Janeiro: Zahar. 
Freitas, K. A. (2015). Ressonância das Imagens da Multidão. Revista Brasileira de Estudos Urbanos e Regionais. Cidades e Insurgências: novos e velhos conflitos, agências e direitos, no 17(3), 17-33. ISSN eletrônico: 2317-1529, 2015.

Hamra, José E. C. (2018) Urbanismo bottom-up: sociedade em rede e processos de urbanização emergentes. Dissertação de mestrado - Instituto de Arquitetura e Urbanismo da Universidade de São Paulo. São Carlos.

Lemos, A. (2008). Mídia Locativa e Território Informacional. In: Arantes, P.; SANTAELLA, L. (Orgs). Estéticas Tecnológicas: Novos Modos de Sentir. São Paulo: EDUC/SP.

Panagoulia, E. (2017). Human Centered Approaches in Urban Analytics and Placemaking. In: CONGRESO DE LA
SOCIEDAD IBERO-AMERICANA DE GRÁFICA DIGITAL, 21., 2017, Concepción, Chile. Anais eletrônicos. Concepción, 2017. Disponível

em: <https://www.proceedings.blucher.com.br/articledetails/human-centered-approaches-in-urban-analytics-andplacemaking-27692>. Acesso em 20 mar. 2018.

Shirky, C. (2011). Cultura da Participação: criatividade e generosidade no mundo conectado. 1a Edição. Rio de Janeiro: Zahar.

Shirky, C. (2012). Lá Vem Todo Mundo: o poder de se organizar sem organizações. 1를 Edição. Rio de Janeiro: 